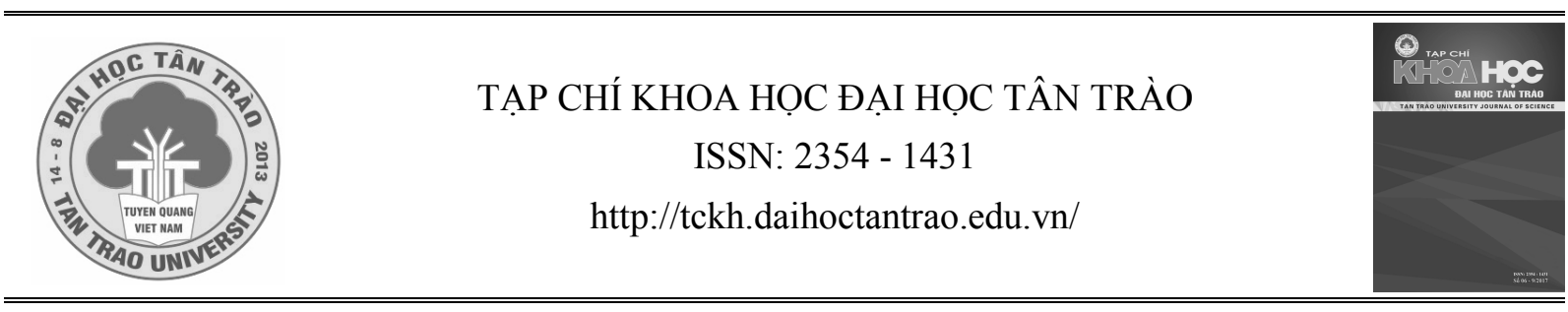

\title{
Thơ văn xuôi và sự giao thoa thể loại
}

\author{
Vũ Quỳnh Loan ${ }^{a^{*}}$ \\ ${ }^{a}$ Truoòng Đại học Tân Trào \\ *Email:loanvantq@gmail.com
}

\section{Thông tin bài viết}

Ngày nhận bài:

06/02/2018

Ngày duyệt đăng:

$10 / 3 / 2018$

\section{Tù khoá:}

Tho văn xuôi;

giao thoa; thể loai;

trũ tình; tụ do.

\section{Tóm tắt}

Thơ văn xuôi là thể thơ ra đời từ nhu cầu tự thân của thời hiện đại. Với khả năng truyền tải hiệu quả những cảm xúc đa chiều, phức tạp của nội tâm con người thời hiện đại, thơ văn xuôi đã ngày càng phát triển mạnh mẽ. Là thể loại ra đời sau, theo đúng quy luật vận động và phát triển thể loại văn học, thơ văn xuôi đã có sự giao thoa với một số thể loại trữ tình như tuỳ bút và thơ tự do.
Thơ văn xuôi là một thể thơ trữ tình hiện đại. Về mặt hình thức, là kết quả của sự tương tác thể loại giữa thơ và văn xuôi. Là thể thơ ra đời bởi nhu cầu thể hiện một cách nồng nhiệt nhất những trạng thái cảm xúc đa chiều, giàu chất suy tưởng, chiêm nghiệm của nhân vật trữ tình. Thơ văn xuôi với tính chất giao thoa và tương tác thể loại tương đối phức tạp nên không thể có một khái niệm có khả năng bao trùm mọi sáng tác.

Về mặt hình thức có hai dạng:

1. Dạng điển hình: những bài thơ không ngắt dòng, có thi tứ và xuất hiện với hình thức những đoạn văn xuôi, ngắn hoặc dài.

2. Dạng không điển hình: là những sáng tác có hình thức gần với thơ tự do, có câu dài ngắn xen nhau, chủ yếu là câu dài chia làm nhiều dòng nhưng không có vần.

Thơ văn xuôi ra đời đã mang đến sự phong phú, đa dạng, linh hoạt và mới mẻ cho nền thơ ca dân tộc. Một thể thơ mới ra đời là dấu hiệu của một bước phát triển của nền văn học, và thơ văn xuôi Việt Nam là bước phát triển vượt bậc từ cơ sở của các thể loại truyền thống đã có chiều dài lịch sử phát triển trong tiến trình thơ ca dân tộc.

Theo Bakhtin, lịch sử văn học "trước hết là lịch sủ hình thành, phát triển, tương tác giữa các thể loại". Dù có sự phân chia thể loại về mặt lí thuyết nhưng trên thực tế, mỗi sáng tác đều không chỉ chịu sự chi phối của riêng một thể loại.

Văn học là sản phẩm tinh thần được sản sinh ra từ một nền văn hoá sinh thành trong môi trường kinh tế, chính trị xã hội nhất định. Manh nha từ đầu thế kỉ XX, nhưng phải đến Thơ Mới 1932 - 1945, thơ văn xuôi mới định hình và xuất hiện với đủ đầy những đặc điểm của một thể loại mới. Thơ văn xuôi là một thể loại mới ra đời từ nhu cầu và quan niệm thẩm mĩ hiện đại.

Nhận xét về sự giao thoa thể loại văn học, Tzvetan Todorov thật có lí khi cho rằng "Một thể loại mói bao giờ cũng là sụ biến đổi của một hoặc vài thể loại khác, bằng sụ đảo ngươc, thay thế và kết hợ" ". Vốn là kết quả của sự giao thoa thể loại trong tiến trình phát triển của văn học Việt Nam hiện đại, thơ văn xuôi rất gần gũi và có sự giao thoa với một số thể loại văn học khác như tuỳ bút văn học và tho tụ do. Ranh giới giữa chúng không phải lúc nào cũng thật rõ ràng. Song, để xác định nội hàm khái niệm tho văn xuôi, chúng tôi nghĩ, cần phải chỉ ra ranh giới giữa tho văn xuôi và các thể loại trung gian đó.

\section{Thơ văn xuôi và văn xuôi trữ tình}

Văn xuôi trữ tình bao gồm các thể loại như tuỳ bút, tản văn, bút kí, truyện trữ tình. Điểm giao thoa giữa thơ trữ tình và các thể loại này là cảm xúc của nhân vật trữ tình là mạch cảm xúc xuyên suốt tác phẩm. 
Một thể loại văn xuôi trữ tình quen thuộc và gần gũi với thơ văn xuôi là tuỳ bút.

Tuỳ bút là tiểu loại văn học giàu tính chất trữ tình nhất, thuộc thể kí văn học, rất gần gũi với tho văn $x u o ̂ i$. Chất trữ tình của tuỳ bút thể hiện ở sự xuất hiện khá cao nồng độ cảm xúc của người viết. Các tác giả biên soạn Tù điển thuật ngũu văn học quan niệm "tuỳ bút (tiếng Pháp: essai, tiếng Anh: essay)" là "một thể thuộc loại hình ki, rất gần với bút kí, ki sụ. Nét nổi bật ở tuỳ bút là qua việc ghi chép nhũng con người và sụ kiện cu thể có thực, tác giả đặc biệt chú trọng đến việc bộc lộ cảm xúc, suy tu và nhận thức đánh giá của mình về con nguời và cuộc sống hiện tại. Cấu trúc của tuỳ bút, nói chung, không bị ràng buộc, câu thúc bởi một cốt truyện cu thể, song nội dung của nó vẫn được triển khai theo một cảm hứng chủ đạo, một tur tưởng chủ đề nhất định. Ngôn ngũ tuỳ bút giàu hình ảnh, chất tho" (3).

Cả hai quan niệm trên đều khẳng định tuỳ bút là tiểu loại giàu chất trữ tình, cấu trúc văn bản tự do, không ràng buộc câu thúc bởi một cốt truyện cụ thể, nội dung được triển khai theo một cảm hứng chủ đạo, ngôn ngữ giàu hình ảnh, giàu chất thơ.

Đọc tác phẩm tuỳ bút có thể dễ dàng nhận ra nghệ thuật trần thuật, vốn là đặc trưng của tự sự, rất gần với trữ tình, nó như một áng thơ văn xuôi với những hình ảnh gợi cảm, rõ nét sắc màu cảm xúc với lối ví von so sánh độc đáo thiên về phương diện tâm lí.

Thơ văn xuôi và tuỳ bút văn học có một số điểm giống nhau cả về hình thức lẫn nội dung.

Về nội dung, chúng đều chú trọng khai thác thế giới nội tâm của cái tôi trữ tình, không bị ràng buộc, câu thúc bởi một cốt truyện cụ thể (tuy có thể chứa đựng một cốt truyện nhưng không lấy việc kể chuyện làm cứu cánh), cùng mang thế mạnh của chất suy tưởng và chiều sâu triết lí. Về hình thức, chúng được trình bày trong dạng thức văn bản văn xuôi, ngôn ngữ giàu hình ảnh và đậm chất thơ.

Trên cái nền chung đó, cả hai thể loại này có cách tổ chức và năng lực gợi cảm khác nhau. Khác với tuỳ bút phải lấy điểm tựa từ một số sự kiện có thực trong đời sống, cái cốt lõi của tuỳ bút bao giờ cũng là một thông tin hiện thực nào đó, và sự thực ấy là cái gốc để mạch văn phát triển, tho văn xuôi hầu như chỉ khai thác dòng suy nghĩ chủ quan của nhân vật trữ tình.

$\left(^{3}\right)$ Lê Bá Hán, Trần Đình Sử, Nguyễn Khắc Phi, Tù điển thuật ngũ văn học, Nxb Đại học Quốc gia, 2000, tr.380
Đến với tho văn xuôi, người đọc cũng thấy được rằng, hình ảnh trong thơ vì được khúc xạ qua cảm nhận chủ quan của nhà thơ mà nhiều khi được đẩy sang bờ tượng trưng, "siêu thực". Trong Chơi giũa mùa trăng của Hàn Mặc Tử, những sự kiện, hình ảnh có thực (hai chị em bơi thuyền trên sông giữa đêm rằm, bến đò thôn chùa Mo, động cát Quảng Bình) cũng biến hoá thành những "huyền ảnh" trong cõi mộng. Đêm rằm trở thành "một đêm siêu hình, vô lượng, tượng trưng của một mùa ao ước, xây bằng châu lệ, làm bằng chiêm bao và hơn nữa, hiện hình của một miền khoái lạc chê chán". Sông thành sông Ngân, bến sông thành bến Hàn Giang, động cát thành chốn "nước Nhược non Bồng, động phủ thần tiên ngàn xưa còn sót lại".

Các hình ảnh trong tuỳ bút không vậy. Chúng có thể được các nhà nghệ sĩ đặt vào rất nhiều trường liên tưởng, với những so sánh, ẩn dụ đầy biến hoá, nhưng vẫn luôn giữ được cái lõi hiện thực. Trong cái nhìn của Nguyễn Tuân, ông lái đò dù biến thành vị tướng xung trận đầy dũng mãnh, thác đá dù như một đội quân ngoan cố và hiểm độc, người đọc vẫn cảm nhận đó là con người, là những sự việc của đời sống thực tại. Những so sánh, liên tưởng của tác giả không làm cho các hình ảnh biến thành siêu thực mà khiến chúng hiện hữu sống động hơn.

Giữa tho văn xuôi và tuỳ bút văn học còn khác nhau ở cách xây dựng nhân vật. Trong tho văn xuôi hầu như chỉ tồn tại một nhân vật duy nhất, đó là nhân vật trữ tình - cái tôi - tác giả. Bài thơ như cuộc chạy đua của ngôn từ với dòng thác cảm xúc ào ạt của thi nhân. Tất nhiên cũng có tác phẩm tho văn xuôi có tới hai nhân vật, ví dụ Cuộc đối thoại của nước (Dạ Thảo Phương) có nhân vật trữ tình "ta" và nhân vật người mẹ - người đối thoại với nhân vật trữ tình. Nhưng, những nhân vật phụ kiểu này chỉ đóng vai trò như cái cớ để nhân vật trữ tình bộc lộ cảm nghĩ chủ quan. Nhân vật trữ tình qua việc soi mình vào nhân vật "phụ" để hiểu mình và tự đối thoại với chính mình.

Trong tuỳ bút, bên cạnh nhân vật trữ tình còn có các nhân vật khác tham gia vào diễn biến sự kiện. Ví dụ, trong Ngườ lái đò sông Đà, bên cạnh nhân vật "tôi" là bức phù điêu tái hiện ông lái đò quả cảm, tài hoa.

Người đọc cũng có thể dễ dàng nhận ra sự khác biệt trong cách tổ chức tác phẩm của tho văn xuôi và tuỳ bút văn hoc. Tuỳ bút văn hoc thường được tổ chức với mạch lập luận tương đối rõ, trái lại mạch vận động trong tho văn xuôi có phần khó nắm bắt, sự liên kết giữa các hình ảnh thơ nhiều khi rất ngẫu hứng. Nội 
dung của tuỳ bút thường được triển khai theo một cảm hứng chủ đạo, một tư tưởng chủ đề nhất định, trong khi nội dung của tho văn xuôi thường chứa đựng những hàm nghĩa biểu đạt đa trị, không cố định.

Có thể thấy tho văn xuôi giống với tuỳ bút văn học ở chỗ, cùng chú ý khai thác những suy nghĩ chủ quan của nhân vật trữ tình, thông qua những câu văn xuôi đầy hình ảnh, mang chiều sâu trí tuệ. Nhưng thơ văn xuôi khác với tuỳ bút ở chỗ, không bám vào sự kiện, hình ảnh mang tính tượng trưng, khơi gợi nhiều trường liên tưởng, cách tổ chức, chủ đề tư tưởng không cố định.

Bên cạnh tuỳ bút, các thể loại văn xuôi trữ tình khác cũng có nhiều điểm giao thoa với thơ văn xuôi. Điểm gần gũi nhất giữa truyện trữ tình, tản văn, những đoạn văn xuôi giàu chất thơ trong một số các tác phẩm tự sự với thơ văn xuôi là chất thơ, là giọng điệu trần thuật giàu nhạc tính. Có thể thấy điểm tương đồng này trong các truyện ngắn của Pautopxki (Lã̃ng quả thông, Tuyết...), trong truyện ngắn của Nguyên Ngọc (Trở lại Mèo $V a c$ )... Có những tác phẩm thơ văn xuôi được các nhà nghiên cứu gắn với các thể loại tự sự: Phạm Xuân Nguyên gọi Cổng tỉnh của Trần Dần là thơ - tiểu thuyết, Jò̀ Joacjx (Trần Dần) là thơ - tiểu thuyết một bẻ đệm" ${ }^{(4)}$. Trong những truyện ngắn của Thạch Lam, Xuân Diệu, sau này là Nguyễn Minh Châu, Hoàng Phủ Ngọc Tường, Nguyễn Trung Thành, Nguyên Ngọc... đều có những tác phẩm văn xuôi tự sự mà trong đó có một số đoạn văn giàu nhạc tính, đậm chất trữ tình.

Tuy vậy, những tác phẩm ấy vẫn là những tác phẩm văn xuôi giàu chất trữ tình chứ không phải là thơ. Đó là kết quả của sự giao thoa thể loại, là biểu hiện của sự xâm nhập của chất thơ vào văn xuôi. Còn thơ văn xuôi là kết quả, là sự thể hiện rõ nét sự xâm nhập của chất văn xuôi vào thơ.

\section{Thơ văn xuôi và thơ tự do}

Không phải ngẫu nhiên mà rất nhiều những nhà nghiên cứu thơ ca hiện đại mỗi khi nhắc đến tho văn $x u o ̂ i$ lại đặt tho tụ do trước, cùng hoặc sau nó. Cũng không phải ngẫu nhiên mà cùng một bài thơ nhưng người thì "xếp chỗ" cho bài thơ đó ở thể thơ tự do, người thì gọi đó là một bài thơ văn xuôi. Có lẽ không chỉ bởi thơ văn xuôi vốn là "hậu duệ" của tho tụ do mà

\footnotetext{
(4) Phạm Xuân Nguyên, Nhà văn nhu Thị Nở, Nxb Hội Nhà văn, Hà Nội, 2014, tr. 125
}

còn là bởi thơ văn xuôi có nhiều điểm rất gần gũi với người anh em này của nó.

Nhà nghiên cứu Nguyễn Đăng Điệp gọi thơ văn xuôi là "điểm văng $x a$ nhất" của thơ ca tự do. Khó có cách gọi nào về thơ văn xuôi hay hơn cách gọi này. Nó khiến cho chúng ta hiểu thế nào là thơ văn xuôi một cách nhanh nhất. Và nó cũng khiến cho bạn đọc mỗi khi chạm vào thể tài thơ văn xuôi lại không thể không nghĩ đến vai trò của thơ tự do - một thể loại văn học đã phá vỡ hệ thống thi pháp của thơ ca cổ điển, thành trì vững chắc của những khuôn khổ, luật lệ gò bó.

Tác giả Hữu Đạt trong cuốn Phong cách hoc và các phong cách chức năng Tiếng Việtcũng cho rằng "Về mặt ngôn ngũ có thể coi thơ văn xuôi là hình thức phát triển cao nhất của tho tụ do".

Ranh giới giữa thơ văn xuôi và thơ tự do quả thật không phải lúc nào cũng rõ ràng. Dù có những điểm giao thoa nhưng giữa hai thể thơ này vẫn có những tiêu chí nhất định để chúng ta phân loại nó. Các tác giả cuốn "Từ điển thuật ngữ văn học" cho rằng, tiêu chí quan trọng nhất để phân định thơ tự do và thơ văn xuôi là tiêu chí có hay không có sự phân dòng: "tho" văn xuôi khác tho tụ do ở chố không phân dòng, không dùng hình thức dòng tho làm đơn vị nhịp điệu" (5).

Chúng ta biết rằng, nếu như thơ tự do vẫn duy trì một đặc điểm hình thức của thơ: văn bản có phân dòng và xếp song song thành hàng, thành khổ như những đơn vị nhịp điệu thì ở thơ văn xuôi, ngay cả đặc điểm hình thức cuối cùng khiến nó có thể được người đọc nhận diện như một văn bản thơ cũng có thể bị tiêu huỷ.

Đây là một cách phân biệt có cơ sở, nó nhấn mạnh vào sự khác biệt về đơn vị cấu tạo nhịp điệu của hai thể thơ. Ở thơ tự do, đơn vị đó là dòng thơ. Trong khi đó, ở thơ văn xuôi, đơn vị đó là đoạn thơ, gồm nhiều dòng thơ hợp lại.

Cách phân biệt này tuy có cơ sở nhưng chưa phải là đã là đúng với mọi trường hợp. Bởi, trong thực tế, có nhiều bài thơ mà đơn vị cấu tạo nhịp điệu là dòng thơ nhưng đó lại là những áng thơ văn xuôi, thậm chí còn là những áng thơ văn xuôi xuất sắc.

\footnotetext{
${ }^{(5)}$ Lê Bá Hán, Trần Đình Sử, Nguyễn Khắc Phi, Tù điển thuật ngũ văn học, Nxb Đại học Quốc gia, 2000, tr.37
} 
Chúng ta hãy thử đặt ra những cơ sở thực tế để những nhà nghiên cứu văn học xếp các bài thơ trên vào thể loại thơ văn xuôi.

Thứ nhất, thông thường thì các câu thơ được giới hạn trong khoảng 10 âm tiết, nhưng có những câu phá vỡ ngưỡng âm tiết này, kéo dài đến mười mấy tiếng nó sẽ có xu hướng văn xuôi hoá về mặt hình thức.

Thứ hai, đúng như ý kiến của Hữu Đạt cho rằng cách tổ chức câu của thơ văn xuôi giống với cách tổ chức câu trong văn xuôi, có nhiều lớp lang, có sự trùng điệp về cấu trúc, sử dụng nhiều thành phần mở rộng, thành phần liên kết. Vì thế mà những bài thơ tự do được tổ chức theo mô hình cấu tạo của câu văn xuôi, dù gồm những câu thơ kéo dài hay những câu thơ có số lượng âm tiết hạn chế, đều có thể được coi là những bài thơ văn xuôi.

Tất nhiên, dạng điển hình nhất của thể thơ văn xuôi vẫn là những bài thơ được trình bày như văn bản văn xuôi, chỉ xuống dòng sau khi đã tạo ra những chiết đoạn và những bài thơ gồm những câu thơ chiếm số lượng dòng in lớn.

Như vậy, nói đến số lượng âm tiết trong một câu thơ vẫn chưa đụng chạm đến bản chất cốt lõi của vấn đề, mặc dù khi áp dụng vào thực tế, đấy sẽ là tiêu chí hữu ích để ta dễ dàng nhận diện các bài thơ. Ngoài tiêu chí dòng thơ chúng tôi đồng quan điểm với nhà nghiên cứu Hữu Đạt, ấy là cần chú trọng đến nghệ thuật tổ chức lời thơ. Nhìn trên trục thời gian có thể thấy, càng ngày, văn học càng đa dạng về thể loại, phát triển mạnh cả về hai cực: cực thơ và cực văn xuôi. Trong mô hình Kraft thơ văn xuôi nằm ở vùng giao thoa giữa hai thể loại trung gian tuỳ bút văn học và thơ tự do.

Giữa thơ văn xuôi, tuỳ bút văn học và thơ tự do có những ranh giới nhất định song cũng có những điểm giao thoa mà người nghiên cứu không thể không thừa nhận. Sẽ là quá cứng nhắc khi cứ quyết liệt đi tìm những tiêu chí để phân định rõ ràng các thể thơ ấy. Không phải không có lí khi Frederich Schlegel nói "Mỗi bài thơ tự nó là một thể loại".

Trong tiến trình phát triển của văn học Việt Nam, sự xâm nhập thể loại đã tạo nên những thể loại mới, trong đó có thơ văn xuôi. Hay nói cách khác, thơ văn xuôi ra đời là kết quả sự tương tác trong đời sống thể loại của văn học hiện đại. Nó cũng là kết quả sự giao thoa giữa văn hoá truyền thống và văn học hiện đại, giữa văn hoá phương Đông và phương Tây.

\section{TÀI LIỆU THAM KHẢO}

1. Hữu Đạt, Phong cách hoc và các phong cách chức năng Tiếng Việt, Nxb Văn hoá Thông tin, 2000;

2. Nguyễn Đăng Điệp, Tho Việt Nam hiện đại, tiến trình và hiện tương, Nxb Văn học, Hà Nội, 2014;

3. Lê Bá Hán, Trần Đình Sử, Nguyễn Khắc Phi, Tù điển thuật ngữ văn học, Nxb Đại học Quốc gia, 2000;

4. Hoàng Ngọc Hiến, Năm bài giảng về thể loại, Nxb Giáo dục, Hà Nội, 1996;

5. Phạm Xuân Nguyên, Nhà văn nhur Thị Nở, Nxb Hội Nhà văn, Hà Nội, 2014.

\section{Poetry prose and the interrelation of style}

Vu Quynh Loan

\section{Article info}

Recieved:

06/02/2018

Accepted:

10/3/2018

\section{Keywords:}

Poetry literary;

Interfere; genre; lyric; free.

\begin{abstract}
Poetry prose is a style which arose from the needs of the present period. With its strength of transmitting diverse and complex feelings of people's soul in the modern period, poetry prose has significantly developed. As a later poetry style, and as the rule of moving and developing of literary genre, poetry prose has been interrelated with some lyrical styles such as free poetry and notes.
\end{abstract}

